\title{
PELATIHAN KEMAMPUAN MENDONGENG KEPADA GURU-GURU PAUD DAN TK MAKANATUT THALIBIN DESA PULANTAN KECAMATAN ALUH- ALUH
}

\section{Storytelling Ability Training for Early Childhood and Kindergarten Teachers Makanatut Thalibin Pulantan Village Aluh-Aluh District}

\section{Jamiatul Hamidah*}

\section{Sri Normuliati}

Istiqamah

Universitas Muhammadiyah

Banjarmasin, Banjarmasin,

Kalimantan Selatan, Indonesia

*email:

midah.beswan@gmail.com

\begin{abstract}
Abstrak
Pengabdian kepada masyarakat ini bertujuan untuk meningkatkan pengetahuan dan keterampilan mendongeng bagi guru dan orang tua siswa PAUD di Desa Pulantan kecamatan Aluh-Aluh. Pengabdian ini dilaksanakan pada hari Kamis, 22 Maret 2018 di PAUD Makanatut Thalibin. Sasaran kegiatan ini adalah para guru PAUD dan orang tua/wali siswa. Alasan memilih sekolah ini adalah karena sekolah yang tergolong jauh dari pusat kota dan termasuk desa binaan program PKH. Metode yang digunakaan dalam pelaksaannya adalah dengan presentasi/ceramah dan simulasi/latihan mendongeng. Setelah dilaksanakan kegiatan ini maka disimpulkan bahwa mendongeng belum menjadi sebuah kebiasaan dan pendekatan dalam pembentukan karakter anakanak baik oleh para guru maupun orang tua. $\mathrm{Hal}$ ini disebabkan para guru maupun orang tua memiliki kemampuan yang sangat minim dalam hal mendongeng. Oleh karena itu, kedepannya diharapkan dilaksanakan pelatihan lanjutan dengan melibatkan lebih banyak guru dan orang tua, serta mendatangkan narasumber yang lebih berkompeten dalam mendongeng seperti Bunda Enik Mintarsih, tokoh pendongeng asal Kalimantan Selatan.
\end{abstract}

Kata Kunci:

Guru

Dongeng

Anak Usia Dini

Keywords:

Teachers

Fairy Tales

Early Chilhood

\begin{abstract}
This community service aims to improve the knowledge and skills of storytelling for teachers and parents of PAUD students in Pulantan Village, Aluh-Aluh sub-district. This dedication was held on Thursday, March 22, 2018, in PAUD Makanatut Talibin. The target of this activity is PAUD teachers and student parents/guardians. The reason for choosing this school is because the schools are classified as far from the city center and include the villages built by the PKH program. The method used in the implementation is by presentation/lecture and storytelling simulation/training. After this activity was carried out, it was concluded that storytelling had not become $a$ habit and approach to the formation of children's character both by teachers and parents. This is because teachers and parents have very little ability in storytelling. Therefore, in the future, it is hoped that further training will be carried out by involving more teachers and parents and bringing in speakers who are more competent in storytelling such as Mother Enik Mintarsih, a storyteller from South Kalimantan.
\end{abstract}

\section{PENDAHULUAN}

Mendongeng merupakan salah satu media pendidikan yang efektif bagi anak, terutama anak-anak pada masa usia emas yaitu sekitar 2-7 tahun. Dunia anak-anak adalah dunia bermain dan berimajinasi. Imajinasi anak dapat dilatih dengan cara mendongeng kepada mereka. Dongeng sebagai salah satu karya sastra, mengandung ek asplorasi mengenai kebenaran manusia. Rokhmansyah (2014) mengemukakan bahwa sastra menawarkan berbagai bentuk kisah yang merangsang pembaca untuk berbuat sesuatu. Apalagi pembacanya adalah anak-anak yang fantasinya baru berkembang dan menerima segala macam cerita terlepas dari cerita itu masuk akal atau tidak.

Anak-anak usia dini (4-6 tahun) yang berada di PAUDTK merupakan masa yang tepat bagi mereka untuk membangun karakter dan kepribadian yang mulia. Seperti yang terdapat dalam cerita monyet dan kurakura, anak-anak diberikan gambaran tentang karakter yang baik dan buruk, yang jujur dan yang curang melalui 
kedua tokoh tersebut. Metode mendongeng merupakan cara yang tepat dalam pendidikan anak usia dini, karena membantu mengembangkan kreativitas, membangkitkan imajinasi, dan membentuk moral yang baik. Di samping itu, dongeng juga berfungsi untuk meningkatkan kemampuan mendengarkan dan menyimak bagi anak. Guru sebagai pelaku utama pendidikan, harus memiliki kemampuan mendongeng agar anak-anak tertarik belajar dan tidak membosankan (Fitroh \& Sari, 2015).

Untuk membangun karakter anak, banyak cara yang dapat dilakukan oleh orang tua di rumah maupun guru di sekolah. Salah satu cara yang dapat dilakukan adalah dengan menerapkan kegiatan mendongeng atau mengenalkan cerita kepada anak. Seorang guru, terutama guru PAUD sebagai tonggak awal dalam pendidikan karakter anak usia dini, diharapkan memiliki kemampuan mendongeng sebagai salah satu metode yang digunakan dalam pembelajaran di dalam kelas (Fitriyyah, 2014).

Sastra anak adalah sastra yang ditujukan untuk anakanak. Nurgiyantoro (2016) mengemukakan bahwa sastra anak dapat berkisah tentang apa saja, bahkan yang menurut ukuran dewasa tidak masuk akal. Misalnya kisah binatang yang dapat berbicara, bertingkah laku, berpikir dan berperasaan layaknya manusia. Sastra anak tidak terbatas pada buku-buku bacaan, pada segala sesuatu yang dicetak secara verbal, sebab dalam dunia kesastraan dikenal sastra lisan dan tulisan.

Sastra lisan adalah sastra yang dilisankan, yang biasanya diwariskan secara turun-temurun melalui cerita. Sedangkan sastra tulisan adalah sastra yang diwariskan melalui tulisan seperti buku-buku yang ditulis. Nurgiyantoro (2016) menegaskan bahwa sastra anak membentang dari nyanyian-nyanyian ninabobo, puisi lagu dolanan, cerita si ibu menjelang anak tidur, bukubuku gambar untuk mengenal dan membelajarkan huruf dan angka, cerita bergambar dengan sedikit tulisan, sampai dengan cerita-cerita petualangan anak, termasuk cerita horor dan misteri, atau cerita-cerita lain yang dikisahkan dengan sudut pandang anak. Diantara jenis tersebut, dongeng merupakan cerita yang paling dekat dengan dunia anak.

Seorang guru dituntut untuk memilih metode pembelajaran yang menarik minat anak didiknya. Metode mendongeng/bercerita merupakan salah satu metode yang diminati anak-anak. Amalia (20I5) menambahkan bahwa guru dapat membantu mengembangkan kemampuan kognitif, afektif, dan psikomotorik anak secara bersama-sama saat menerapkan metode bercerita di tingkat PAUD. Ketika mendengarkan dan mencerna cerita, anak belajar pengetahuan memahami alur cerita dan nilai moral dari cerita. Dengan metode bercerita, anak belajar merasakan dan memaknai tipe-tipe dari cerita. Melalui cerita, anak secara mental dan psikologis belajar menirukan atau bermain peran sesuai cerita. Bercerita juga dapat mengeratkan hubungan psikologis antara guru dengan anak didiknya, maupun antara orangtua dengan anaknya di rumah.

Nurgiyantoro (2016) menyatakan bahwa dongeng merupakan bentuk cerita fantasi, bersifat universal, dan dapat dipahami sebagai cerita yang tidak benar-benar terjadi, bahkan dalam banyak hal sering tidak masuk akal. Menurut Sugiarto (20I5) “Dongeng adalah cerita yang berdasarkan pada angan-angan atau khayalan seseorang yang kemudian diceritakan secara turun-temurun dari generasi ke generasi. Karena hanya khayalan, peristiwaperistiwa dalam sebuah dongeng adalah peristiwa yang tidak benar-benar terjadi, misalnya kejadian-kejadian aneh pada zaman dahulu. Meskipun demikian, tak jarang dongeng dikait-kaitkan dengan sesuatu yang ada di masyarakat tempat dongeng itu berasal.” Dalam Kamus Besar Bahasa Indonesia, dongeng didefinisikan sebagai cerita yang tidak benar-benar terjadi (terutama tentang kejadian zaman dulu yang aneh-aneh); perkataan (berita) yang bukan-bukan atau tidak benar. Haryanta (20I2) “Dongeng adalah cerita yang lahir berdasarkan khayalan semata atau bersifat imajinatif. Pada umumnya, tokoh- 
tokoh dongeng tersebut berupa binatang, seperti kancil, serigala, kura-kura, dan sebagainya; cerita yang tidak benar-benar terjadi (terutama tentang kejadian zaman dulu yang bersifat aneh); perkataan (berita) yang bukanbukan atau tidak benar." Dari beberapa definisi tersebut, dapat disimpulkan bahwa dongeng merupakan cerita imajinatif yang disampaikan secara turun-temurun oleh masyarakat.

Menurut Sugiarto (2015) “Dongeng terkadang bisa membawa pendengarnya hanyut dalam dunia fantasi, bergantung cara penyampaian dongeng tersebut. Adapun fungsi dongeng antara lain adalah untuk menyampaikan ajaran moral (mendidik) dan untuk menghibur. Dongeng juga biasanya mencerminkan nilai, kepercayaan, dan adat suatu daerah.” Nurgiyantoro (2016) sebagai bagian dari cerita rakyat, dongeng berfungsi untuk memberikan hiburan dan sarana ampuh untuk mewariskan nilai-nilai yang diyakini kebenarannya oleh masyarakat. Dongeng bahkan dianggap sebagai satu-satunya cara untuk mengajarkan nilai moral. Dongeng sering mengisahkan penderitaan tokoh, namun karena kejujuran dan ketahanujiannya tokoh tersebut mendapat imbalan yang menyenangkan. Jadi, moral dongeng dapat juga berwujud peringatan dan atau sindiran bagi orang yang berbuat jahat.

Haryanta (2012) mendefinisikan 6 jenis dongeng, yaitu dongeng etiologi, dongeng fabula, dongeng hewan, dongeng jenaka, dongeng mitologi, dan dongeng kosmogoni. Dongeng etiologi adalah dongeng yang menceritakan tentang asal-usul sesuatu. Dongeng fabula adalah dongeng entang dunia binatang yang dapat bercakap-cakap sebagaimana manusia. Dongeng hewan merupakan nama lain dari dongeng fabula. Dongeng jenaka adalah dongeng pelipur lara, dongeng yang menghibur. Dongeng mitologi adalah dongeng tradisional mengenai asal-usul dan kepercayaan suau bangsa. Dongeng kosmogoni adalah dongeng tentang penciptaan alam semesta.
Nurgiyantoro (2016) mengklasifikasikan dongeng menjadi 2 bagian, yaitu dongeng klasik dan dongeng modern. Dongeng klasik adalah cerita dongeng yang telah muncul sejak zaman dahulu yang telah mewaris secara turun-temurun. Contoh dongeng klasik di Indonesia adalah dongeng Timun Emas, Bawang Merah dan Bawang Putih, serta dongeng pengantar tidur. Dongeng modern adalah cerita fantasi modern atau dongeng yang sengaja ditulis sebagai salah satu bentuk karya sastra, ditulis secara sadar, dengan mencantumkan nama pengarangnya. Contoh dongeng modern adalah Harry Potter dan The Lord of The Rings.

Di daerah yang jauh dari akses bahan bacaan, sangat penting untuk mengenalkan cerita-cerita yang mampu menggugah keingintahuan peserta didik. Karena bagi mereka membeli buku dan membaca cerita bukanlah kegiatan yang bisa dilakukan di sela waktu luang. Hal ini dikarenakan ketidakmampuan untuk membeli buku dan juga kurangnya kesadaran para orangtua untuk mengenalkan bahan bacaan sejak dini kepada anak. Lewat tradisi mendongeng di tingkat PAUD-TK, para guru bisa mengenalkan pengalaman membaca kepada peserta didik (Dewan, 20I3).

Salah satu daerah yang jauh dari aspek bahan bacaan adalah Kecamatan Aluh-aluh, kabupaten BanjarKalimantan Selatan merupakan wilayah yang letaknya tersebar di daerah sungai. Menurut informasi, tingkat pendidikan di daerah tersebut masih rendah. Hal ini disebabkan oleh salah satunya adalah sulitnya wilayah untuk dijangkau, tidak ada transportasi darat yang bisa dilalui, hanya melalui transportasi sungai (kelotok). Di kecamatan Aluh-aluh, terdapat 25 PAUD-TK yang tersebar di 14 kelurahan. Jumlah guru dalam satu sekolah rata-rata 2-3 orang yang latar kualifikasi pendidikannya hanya tamat SMP atau SMA. Berdasarkan survei awal, metode mengajar guru PAUD-TK masih kurang bervariasi, media belajar terbatas, dan minat baca masih rendah. Tujuan diadakannya pelatihan ini adalah untuk memberikan pengetahuan kepada Guru 
PAUD-TK akan manfaat mendongeng untuk pendidikan anak usia dini, melatih dan meningkatkan kemampuan mendongeng bagi Guru PAUD-TK, dan meningkatkan minat baca anak-anak melalui hibah buku dongeng ke sekolah.

\section{METODOLOGI}

Kegiatan ini dilaksanakan dalam satu hari, mulai jam 09.00- II.00 WITA, pada hari Kamis, 22 Maret 20I8, bertempat di Sekolah PAUD Makanatut Thalibin Desa Pulantan RT.05 Kecamatan Aluh-aluh. Lokasi sekolah berada di seberang sungai, sehingga harus menggunakan transportasi kelotok untuk ke sekolah tersebut. Peserta kegiatan adalah guru-guru, para siswa, dan orang tua/wali siswa. Kegiatan ini juga dihadiri oleh Camat Aluh-Aluh dan kepala Desa Pulantan.

Sasaran utama dalam kegiatan ini adalah meningkatkan kemampuan mengajar guru-guru PAUD dan TK Makanatut Thalibin di desa Pulantan, Kecamatan Aluhaluh. Namun dalam pelaksanaan kegiatan, pendamping PKH yang menjembatani kegiatan ini menyarankan untuk melibatkan orang tua siswa. Peserta kegiatan terdiri dari 6 orang guru, 33 siswa, dan 30 orang tua/wali siswa yang keseluruhannya adalah perempuan.

Materi yang disampaikan dalam kegiatan ini adalah tentang fungsi dan manfaat dongeng serta memberikan contoh secara langsung bagaimana cara mendongeng yang disukai anak-anak. Metode penyampaian dengan presentasi dan simulasi yang dilakukan oleh dosen dan mahasiswa prodi pendidikan Bahasa Indonesia.

\section{HASIL DAN PEMBAHASAN}

Pelatihan peningkatan kemampuan mendongeng bagi guru dan orang tua siswa di PAUD Makanatut Thalibin ternyata mendapat respon yang sangat baik dan positif dari peserta kegiatan. Hal ini tampak pada antusiasme peserta dalam bertanya kepada pemateri. Diantara salah satu peserta bahkan menyatakan minatnya untuk menerapkan metode mendongeng dalam mendidik anaknya. Namun secara jujur peserta tersebut mengakui bahwa beliau tidak bisa membaca dan menulis. Inilah fakta yang ditemui di lapangan bahwa masih ada sebagian orang tua yang tidak bisa membaca dan menulis, sehingga jauh dari harapan untuk dapat mengajari anaknya di rumah. Mereka umumnya hanya mengandalkan pendidikan anaknya kepada sekolah.

Fakta lain yang ditemukan pada saat pelaksanaan pengabdian kepada masyarakat ini adalah kurangnya kepedulian orang tua terhadap pendidikan anak di rumah. Misalnya ketika ditanyakan apa yang dilakukan orang tua terutama ibu pada siang dan malam hari saat anak berada di rumah, sebagian besar menjawab jika tidak ada pekerjaan maka orang tua sering menonton televisi dan anak ikut dilibatkan. Menjelang tidur malam hari hampir seluruh orang tua menyatakan tidak pernah mengantar anaknya tidur sambil bercerita. Hal ini bagi tim pelaksana menjadi bahan masukkan untuk para orang tua. Pendidikan karakter bagi anak usia dini dapat dimulai dari membangun kebiasan bercerita atau mendongeng menjelang anak tidur pada malam hari.

Bagi para guru yang berhadir, kegiatan pelatihan ini meningkatkan pengetahuan dan kemampuan mereka dalam melakukan proses belajar-mengajar di kelas. Hibah buku kumpulan dongeng yang diberikan oleh tim pelaksana, menjadi sumber bacaan yang bermanfaat untuk menambah pengetahuan. Pada akhir kegiatan, kepala sekolah sekaligus ketua yayasan menyampaikan harapannya agar pelatihan ini dapat dilaksanakan kembali secara berkelanjutan dengan melibatkan lebih banyak guru dan orang tua khususnya di Kecamatan Aluh-Aluh Kabupaten Banjar. Hal tersebut juga didukung penuh oleh aparat desa yang saat itu dihadiri oleh isteri kepala desa, serta didukung penuh oleh Camat Aluh-Aluh yang berjanji siap menyediakan tempat acara jika ingin mengadakan pelatihan dengan jumlah peserta yang lebih banyak. 


\section{KESIMPULAN}

Berdasarkan hasil wawancara dan pengamatan di lapangan, maka disimpulkan bahwa mendongeng belum menjadi sebuah kebiasaan dan pendekatan dalam pembentukan karakter anak-anak baik oleh para guru maupun orang tua. Hal ini disebabkan para guru maupun orang tua memiliki kemampuan yang sangat minim dalam hal mendongeng. Oleh karena itu, kedepannya diharapkan dilaksanakan pelatihan lanjutan dengan melibatkan lebih banyak guru dan orang tua, serta mendatangkan narasumber yang lebih berkompeten dalam mendongeng seperti Bunda Enik Mintarsih, tokoh pendongeng asal Kalimantan Selatan. Pendidikan karakter bagi siswa/peserta didik dapat dikembangkan dengan melakukan pendekatan kepada guru dan orang tua. Oleh karena itu, kami menyarankan bagi tim yang ingin melaksanakan pengabdian kepada masyarakat agar melakukan pelatihan metode pengajaran lainnya yang mudah, digemari oleh siswa, dan menyenangkan dalam proses pembelajaran. Bagi peserta yang telah memperoleh pelatihan diharapkan dapat terus menerapkan dan mengembangkan kemampuannya dalam mendongeng.

\section{REFERENSI}

Amalia, T.Z. \& Sa'diyah, Z. 2015. Bercerita sebagai Metode Mengajar bagi Guru Raudlatul Athfal dalam Mengembangkan Kemampuan Dasar Bahasa Anak Usia Dini di Desa Ngembalrejo Bae, Kudus. ThufuLA: Jurnal Inovasi Pendidikan Guru Raudhatul Athfal. 3(2):334-353.

Dewan, P. 2013. Reading Matters in the Academic Library. Reference \& User Services Quarterly. 52(4):309-319.

Fitriyyah, D. 20I4. Pendidikan Karakter Melalui Kegiatan Mendongeng di TK ABA Karangduwur dan TK Masyithoh Petanahan Kabupaten Kebumen. Jurnal Pendidikan Agama Islam. I I(2): I69-I84.

Fitroh, S.F. \& Sari, E.D.N. 20 I5. Dongeng Sebagai Media Penanaman Karakter Pada Anak Usia Dini.
Jurnal PG-PAUD Trunojoyo: Jurnal Pendidikan dan Pembelajaran Anak Usia Dini. 2(2):95- 105.

Haryanta, A.T. 20I2. Kamus Kebahasaan dan Kesusastraan. Surakarta: Aksara Sinergi Media.

Nurgiyantoro, B. 2016. Sastra Anak, Pengantar Pemahaman Dunia Anak. Yogyakarta: Gadjah Mada University Press.

Rokhmansyah, A. 2014. Studi dan Pengkajian Sastra, Perkenalan Awal terhadap Ilmu Sastra. Yogyakarta: Graha IImu.

Sugiarto, E. 2015. Mengenal Sastra Lama. Yogyakarta: Andi Offset. 